\section{Transversalidade no Centro de} Estudos Africanos em Moçambique, 1976-1986: a construção de uma nova visão nas ciências sociais

\section{Colin Darch}

University of Cape Town / Cidade do Cabo, África do Sul
v colin.darch@gmail.com

\section{RESUMO}

Neste artigo reflito sobre um estudo de caso que aproveita dos conceitos antropológicos de transversalidade e olhar cruzado. Interrogo minha própria experiência de trabalho num centro de pesquisa em Moçambique na década de 1980, em meio a um conflito armado pós-independência, desencadeado por rebeldes e apoiado pelo regime sul-africano de apartheid. Anglófono, com experiência de trabalho em diversos países africanos, cheguei a Moçambique em 1979 incapaz de falar português ou distinguir na vida quotidiana as características locais daqueles herdados do poder colonial, uma vez que ambos me eram alheios. Além disso, a pesquisa e as práticas pedagógicas utilizadas no Centro de Estudos Africanos eram inovadoras e fora da prática normal acadêmica da época. Desta experiência, tiro três conclusões: que é necessário abordar uma nova cultura e uma nova linguagem tão livre quanto possível das expectativas anteriores, como os antropólogos costumam fazer; que, pelo menos na África, estamos agora, quarenta anos mais tarde, vivendo numa época em que o fluxo aberto de informações e experiências está cada vez mais ameaçado e, assim também, a possibilidade de transversalidades; e que, embora vivamos em circunstâncias e condições materiais que estão fora do nosso controle, como Marx aponta, fazemos nossas próprias escolhas sobre nossas próprias trajetórias.
DoI

http://dx.doi.org/10.11606/ 2179-0892.ra.2017.141742

\section{PaLAVRas-chave}

Moçambique,

Centros de pesquisa, experiências interculturais, Centro de Estudos Africanos (Maputo), África do Sul, documentação, Aquino de Bragança, Ruth First 


\section{Introdução'}

Falar dos olhares cruzados ou dos pertencimentos transversais é falar de múltiplas interações interligadas. Essas incluem a interface entre a experiência ao longo da vida do observador e os fenômenos sociais sendo observados; o encontro brutal entre vários colonialismos bem diferenciados - o português, o britânico, o francês, o belga -e as multiplicidades dos colonizados; e no mínimo as barreiras que ao mesmo tempo são portas abrindo a outros universos de saberes - de raça, de gênero, de idioma. Essas perspectivas são, na sua essência, trans e multidisciplinares, estimulando diálogo, tentando desconstruir as relações de dominação, misturando teorias e conceitos de formas inovadoras e com variados níveis de sucesso, alcançando novos abordagens ou sobrevivendo os desastres intelectuais.

Tanto por sorte como intencionalmente, uma grande parte da minha vida profissional e pessoal tem consistido numa série de travessias, percursos e até colisões com o chamado "outro"; com línguas, culturas e sociedades em que me encontrei ao mesmo tempo como intruso e como convidado bem-vindo, como novato e às vezes como portador de sabedoria alienígena. O fato é que, agora sul-africano assumido e orgulhoso, nasci e cresci na Inglaterra, pequena ilha europeia. Aos 18 anos de idade, no início dos anos 1960, inquieto por natureza, viajei por terra durante quase um ano pela França e Espanha para a África setentrional, pegando carona em Marrocos, Argélia, Tunísia, Líbia e Egito, indo de barco ao Líbano e explorando a Síria, Iraque e Turquia. Embora esses encontros fossem superficiais, a sofisticação e generosidade desses povos, dessas culturas e civilizações, tirou o meu fôlego e me deixou faminto para mais oportunidades para explorar o mundo. Minha boa fortuna foi, portanto, aprender cedo que não sabia nada, como Sócrates

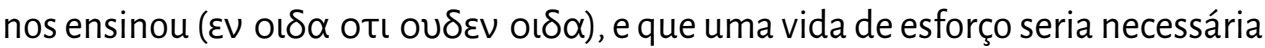
para mudar isso, mesmo um pouco, sem qualquer garantia de sucesso.

Assim, entre 1970 e 1992 vivi e trabalhei durante anos na Etiópia, na Tanzânia, em Moçambique, no Zimbabwe, e no Brasil, chegando à África do Sul mais ou menos na altura de democratização, e aprendendo ao longo do tempo um pouco de amárico (idioma agora por mim esquecido), algumas palavras de suaíli, e este português artesanal no qual escrevo agora. Viver num país é qualitativamente diferente de simplesmente visitá-lo. A gente come a comida, escuta a música, talvez aprenda a apreciar um pouco a poesia e a literatura, entende o que faz as pessoas rirem. Com muita sorte, podemos chegar ao ponto de alguém dizer, sem pensar: "Ah, Colin, mswahili wewe!" (Colin, você é um suaíli), deixando você próprio a decidir se o comentário era um elogio ou uma crítica.

Como teorizar, então, minha própria vida como eu a vivi, com o que pudessem ou não ter sido suas transversalidades, seus olhares inusitados (tanto dados como recebidos)? Vou fazê-lo desligando os holofotes de mim mesmo e da
1 Este texto é uma revisão e expansão de uma fala oferecida por mim no Seminário Especial "Olhares Cruzados, Pertencimentos Transversais", na $30^{\mathrm{a}}$ Reunião Brasileira da Antropologia, (UFPB, João Pessoa), em 4 de agosto de 2016. Alguns de seus elementos foram publicados anteriormente em inglês (Darch, 2014: 38-43), e em português (Darch, 2016: 115-130). Meus agradecimentos a Clinarete Munguambe, David Hedges, Gary Littlejohn, Jacques Depelchin, Laura Moutinho, Paolo Israel e aos dois pareceristas anônimos por suas sugestões e correções de erros de fato e interpretação. 
minha experiência direta própria, saindo do centro do palco, e me concentrando no trabal ho em Moçambique entre 1978/1979 e 1987. Estive nesse período no país como investigador e documentalista do Centro de Estudos Africanos (CEA) em Maputo, no auge da luta entre o projeto revolucionário marxista do movimento de libertação, a Frelimo, e o regime intervencionista de apartheid na África do Sul.

Fui um dos pesquisadores recrutados na Tanzânia pela professora, jornalista e militante sul-africana Ruth First ${ }^{2}$ em 1978, quando ela estava quase pronta para assumir a função de diretora científica no Centro de Estudos Africanos ${ }^{3}$ da Universidade Eduardo Mondlane em Maputo, Moçambique. No início do ano, um anúncio tinha circulado informalmente de mão em mão na Universidade de Dar es Salaam, onde eu trabal hava, dizendo que o Centro estava à procura de um documentalista, entre outros especialistas. Eu me candidatei com êxito.

Ruth sempre entendeu com muita clareza que o nosso Centro necessitava de acesso sólido e bem organizado a vários tipos de leitura, para que os nossos estudantes pudessem adquirir a capacidade de ler criticamente. Isso era tão importante quanto a prática de trabalho de campo. Ruth garantiu que um financiamento parcimonioso, mas adequado - fornecido por doadores europeus -, estivesse disponível para a compra de livros, revistas e jornais, organizou uma sala com equipamento necessário, espaço e estantes para armazená-los, e contratou uma pequena equipa de apoio para ajudar na construção de um núcleo de documentação que virou ao longo do tempo uma coleção eficaz e bem orientada de materiais impressos e duplicados. Nos finais dos anos 70 e início dos anos 80, enfrentamos diversas dificuldades. Os materiais impressos vindo de outros países levavam meses a chegar em Maputo, e a obtenção de jornais sul-africanos era às vezes quase impossível. O Centro assinou, por exemplo, ao Rand Daily Mail, publicação liberal, mas nunca recebeu um único exemplar-possivelmente porque eram confiscados pela polícia de segurança sul-africana. Quando o conflito armado com os rebeldes da Renamo intensificou-se, na década de 1980, tivemos cada vez mais dificuldade em alcançar os materiais de pesquisa necessários.

No contexto global da derrota dos EUA no Vietnã, este projeto parecia realizável para muitos de nós, jovens esquerdistas. No entanto, em 1979, quando cheguei a Maputo, não conhecia quase nada de língua portuguesa e não tinha como distinguir em nenhuma área da vida cotidiana "o colonizado" de "o colonizador", ou seja, a metrópole da periferia. Quase tudo era novo, estranho e difícil de navegar: a minha capacidade de fazer investigação como "uma atividade científica autônoma e autoconfiante" respondendo a "problemas e questões suscitados direta ou indiretamente por africanos" (Hountondji, 2008: 149, 157) era bastante limitada. Assim, esta reflexão tenta aproveitar da ideia do olhar transversal para entender melhor esse encontro entre meu africanismo meio-britânico e o mundo da "Lusofonia-na-África". Ao fazer isso, e para o qual peço desculpas
$2 \quad$ Desde os dias de estudante, Ruth First (1925-1982), comunista e filha de uma família de comunistas, tinha sido uma oponente ativa do sistema de apartheid na África do Sul. Jornalista de profissão, estava entre os réus no notório processo "de traição", entre 1956 e 1961, ao lado de 156 outras figuras da militância organizada contra o apartheid. Quando o governo impôs um estado de emergência após o massacre de manifestantes negros em Sharpeville, em 1960, ela foi "banida", ou seja, proibida de participar em qualquer atividade política, reunir-se com pessoas, viajar, publicar textos, ou até ser citado por outros. Em 1963, ela foi presa e mantida em isolamento durante 117 dias de interrogações, sendo em seguida classificada "imigrante proibida" e expulsa do país. Após alguns anos trabalhando em universidades inglesas, virou diretora científica do Centro de Estudos Africanos em Moçambique a partir de 1978 , um emprego que considerou uma oportunidade de participar na transformação social na África Austral como região.

3 O Centro de Estudos Africanos foi estabelecido em 1976 por Aquino de Bragança e Fernando Ganhão (primeiro reitor da Universidade Eduardo Mondlane) para resolver o problema, de curto prazo, da ausência de capacidade adequada nas ciências sociais após a independência. Ainda funciona hoje, mais que quarenta anos depois. O nome do Centro foi escoIhido em homenagem a um grupo de estudos organizado nos anos 50 e 60 em Lisboa por nacionalistas africanos. 
dos estimados leitores, o foco muda inevitavelmente enquanto a história avança, ultrapassando e voltando a meu itinerário pessoal, entre uma discussão contextual da pesquisa e do ensino do Centro de Estudos Africanos, bem como (de uma forma limitada), a importância intelectual e pessoal de Aquino de Bragança e Ruth First, respectivamente, diretor e diretora científica do Centro.

\section{O IMPULSO À MEMORIALIZAÇÃO}

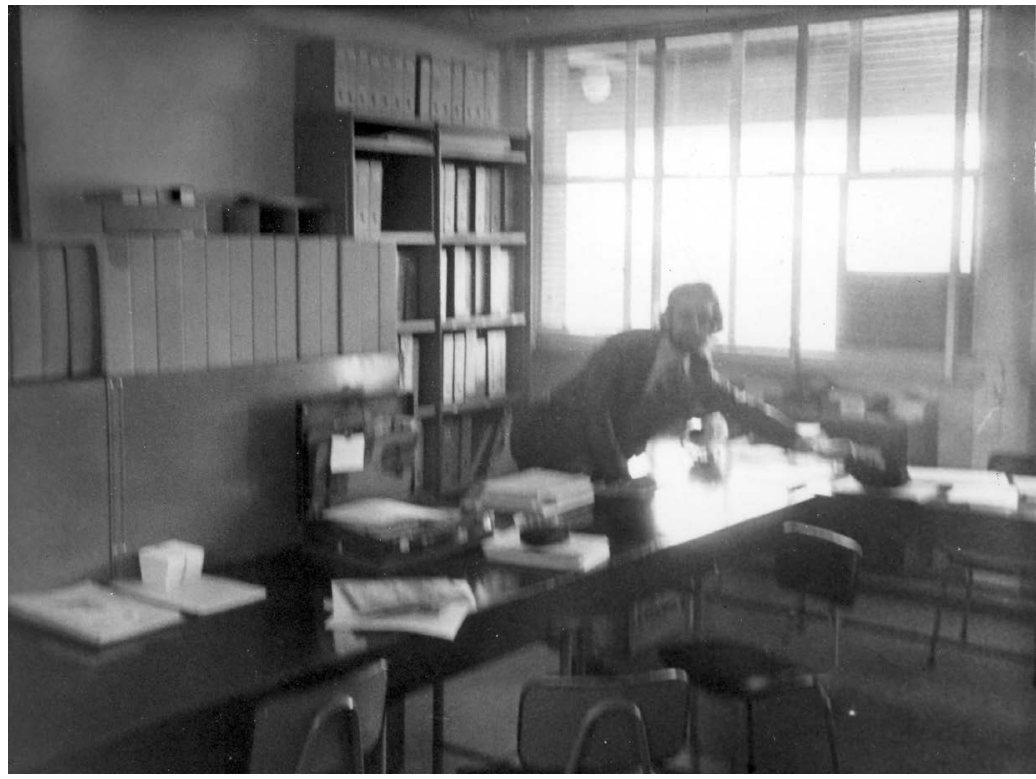

Ao longo do tempo, a experiência do Centro de Estudos Africanos tem atraído um certo nível da atenção acadêmica - ora polêmica e crítica, mas muitas vezes elogiosa. Dado que as personalidades dirigentes do Centro, Aquino de Bragança e Ruth First, ambas morreram violentamente, vítimas da luta contra o apartheid, essa tendência a uma memorialização respeitosa é bem compreensível, tanto política como emocionalmente. Também é necessário pontuar que os anos entre 1976 e 1986 foram, num certo sentido, o que Ribeiro Thomaz (2012: 229) chamou de "os tempos heroicos", o que nos obriga a nos proteger contra um certo tipo de romantismo revolucionário, com heróis intelectuais martirizados, com o individualismo subordinado a um propósito comum, e com uma forte nostalgia para uma idade dourada perdida. ${ }^{4}$

No entanto, uma das consequências do impulso à memorialização tem sido o que pode ser visto como um excesso de ênfase sobre as figuras de Aquino de Bragança e Ruth First e, especialmente na literatura de língua inglesa, uma subestimação do significado político e intelectual de Aquino. $O$ foco na personalidade dominante e na liderança extraordinária de Ruth First, e no Curso de Desenvolvimento entre 1979 e 1982, embora indubitavelmente necessário, corre o risco de perder a variedade impressionante das atividades do Centro. ${ }^{5} \mathrm{Não}$ se deve ignorar o trabalho da Oficina de História (na qual Ruth não estava diretamente envolvida ${ }^{6}$ ) e as suas publicações - incluindo as edições do boletim Não Vamos Esquecer, os dois relatórios sobre a situação na província de Cabo Delgado, e a coletânea de artigos selecionados do jornal O Africano, publicado eventualmente no Brasil (Soares e Zamparoni, 1992). Também vale observar a orientação fundadora do Centro na direção da pesquisa histórica (Bragança e O'Laughlin, 1996: 114). Foi prestada também pouca atenção às pesquisas do Núcleo da África Austral. Isso foi parcialmente reconhecido dentro do Centro, mesmo nos meados da década de 1980, quando um

\section{Figura 1}

O autor trabalhando no Núcleo de Documentação do CEA, provavelmente em 1982 ou 1983. Foto: José Maria Nunes Pereira, coleção particular do autor.

4 Curiosamente, há muitos anos, Ali Mazrui escreveu o que equivalia a um ataque a um suposto "olhar sonhador" que os românticos esquerdistas europeus teriam adquirido em relação à Tanzânia, chamando assim esse fenômeno "Tanzaphilia" (Mazrui, 1967). Esta foi talvez uma das primeiras críticas aos "pés vermelhos", embora Mazrui não use o termo.

5 A natureza inovadora, tanto do ponto de vista pedagógico como epistemológico, de pesquisa e ensino, da direção de Ruth já foi bastante bem documentada em vários artigos publicados logo após a sua morte, alguns em inglês e outros em português (por exemplo Bragança e O'Laughlin, 1996).

6 Ruth nunca tivera muito interesse em pesquisa histórica e o foco original, em 1976, antes da sua chegada, de 
relatório interno que incluiu uma listagem de uma gama impressionante das atividades de pesquisa e ensino, também comentou que, pelo menos nos primeiros anos, "o Curso de Desenvolvimento dominou de tal forma a vida do Centro que chegou quase a ser a sua raison d'être" (UEM, 1985: 5).

A literatura sobre Aquino, Ruth e o CEA pode ser dividida em duas categorias principais. A primeira é o que poderia ser denominado "narrativas privilegiadas", ou seja, textos escritos por pesquisadores que eram funcionários do Centro durante os "tempos heroicos" - enfrentando assim o perigo óbvio de privilegiar a experiência em vez da análise. A segunda categoria consiste num punhado de comentários mais críticos e ocasionalmente hostis, produzidos por estudiosos que nunca trabalharam no Centro.

A gama de literatura da primeira categoria focada nas principais figuras do Centro de Estudos Africanos, Aquino de Bragança ${ }^{7}$ e Ruth First, é surpreendentemente extensa e produzida por um período de tempo longo. ${ }^{8}$ Conferências e seminários têm sido realizados, palestras e apresentações feitas, sítios e páginas da Web postados, livros e artigos publicados e monumentos erigidos há três décadas, e em três continentes, desde as mortes precoces e violentas (já mencionadas) dos dois nas mãos do regime sul-africano de apartheid - Ruth assassinada por uma carta-bomba no seu gabinete na universidade em agosto de 1982, Aquino morto com Presidente Samora Machel e outros no desastre aéreo de Mbuzini em outubro de 1986.

Sabemos que as memórias não residem numa forma pura e imutável em nossos cérebros. Pelo contrário, são reconstruídas a cada vez que lembramo-nos de qualquer coisa, no presente, no próprio ato de recordação. As diversas manifestações de lembrança de Aquino e Ruth pelos seus contemporâneos e outros ao longo do tempo é, portanto, um processo contínuo e fluido de reconstrução imaginária de duas pessoas que já não existem mais. Essa rememoração cumpre fins que têm, quiçá, mais a ver com o atual momento político e cultural, que com o que Proust chamava "as coisas como elas eram", num passado perdido e irrecuperável.

O óbvio é que existe um forte desejo para comemorar-continuamente - estas duas figuras, cujas vidas cruzaram-se de forma mais significativa no final de década 1970 e no início de década 1980, quando juntos constituíram a direção do Centro de Estudos Africanos, em Maputo. Ambos contavam, num grau elevado, com o olho analítico do jornalista radical, uma sensibilidade desenvolvida de justiça social, e uma ampla gama de compromissos com lutas de libertação no hemisfério sul. Muito diferentes na personalidade, os dois eram professores influentes e carismáticos, cujo impacto sobre as vidas dos seus alunos era forte e de longa duração - como testemunhou Alexandrino José em sua intervenção no Dia Ruth First em 2012. José foi pesquisador "investigação no subsistema da África Austral, com ênfase na história" foi logo modificado (Bragança e O’Laughlin, 1996: 114). Ela escreveu, na introdução ao n.1 da revista Estudos Moçambicanos que "não será uma revista de história, mas apoiar-se-á (...) no trabalho de uma jovem nova escola de historiadores moçambicanos (...)".

7 Aquino de Bragança (1928-1986) era natural de Coa mas mudou-se para Moçambique e, em seguida para a França, ainda jovem. Envolveu-se nas atividades políticas anticoloniais, e trabalhou em Argel para a Conferência das Organizações Nacionalistas das Colônias Portuguesas (CONCP) -órgão coordenador dos movimentos de libertação em Angola, Guiné e Moçambique-durante muitos anos. Era ativo como jornalista, principalmente nos periódicos progressistas da expressão francesa. Confidente e assessor do Presidente Samora Machel, voltou a Moçambique na altura de independência em 1975 para assumir a direcção do CEA. Realizou diversas missões diplomáticas semiclandestinas, adquirindo o apelido de "o submarino" nos circuitos partidários, em homenagem à sua discrição. Morreu ao lado de Samora Machel no desastre aéreo de Mbuzini em outubro de 1986, um evento que muitos acreditam ter sido causado por ação sul-africana-embora isso nunca tenha sido provado.

8 Falta espaço de denominar aqui todos os eventos e as publicações. Posso salientar que uma série de palestras dedicada à memória de Ruth First foi inaugurada tão cedo como 
no Centro durante muitos anos e foi nomeado diretor por algum tempo na década de $1980 .^{9}$

Há, de fato, duas linhas identificáveis para o impulso de comemorar Aquino e Ruth. A primeira e mais antiga linha a surgir é a de continuar o trabalho acadêmico no qual os dois se engajaram, tentando assim manter vivo a metodologia, a epistemologia e o engajamento político deles. Mas um tal projeto de recuperação, hoje em dia, numa época na qual todo o mundo encontra-se obrigatoriamente submetido às exigências da "carreira acadêmica", pareceme quixotesco e condenado ao fracasso. Quem é que tem vontade de publicar trabalhos sem eles terem a sua identificação como autor? Quem é que aceita a subordinação dos seus interesses pessoais durante anos de pesquisa às decisões de uma coletiva de colegas?

A segunda, que vem muito mais tarde, numa altura quando Aquino e Ruth já começaram a ser esquecidos como indivíduos vivos, é a memória pessoal, tentativas de caracterização da pessoa viva como era. Se examinarmos a história da comemoração de Aquino e Ruth nessas últimas três décadas, vemos a segunda tendência aumentar significativamente em importância. Mas, para já, vamos passar a outro foco, a questão das práticas de pesquisa do Centro e as críticas feitas nelas.

\section{O CURSO DE DESENVOLVIMENTO}

Sem qualquer dúvida, a joia da coroa do Centro na fase de Ruth em Maputo foi o Curso de Desenvolvimento, um curso de dois anos para jovens quadros do Estado e do Partido (Bragança e O'Laughlin, 1996). A ideia fundamental não era a transmissão de um conjunto de conhecimentos como tal, mas sim ensinar esses jovens a analisar os problemas de forma que pudessem mais tarde contribuir para o desenvolvimento de políticas para a transformação social. Os estudantes não eram selecionados de acordo com critérios acadêmicos tradicionais, mas por suas responsabilidades nas estruturas estatais e partidárias. Alguns não tinham, portanto, formalmente as habilitações para participar de um curso de pós-graduação. Infelizmente, esta foi uma das razões, apesar dos melhores esforços de Ruth, pelas quais os graduados não receberam diplomas, apenas certificados de participação.

Os métodos pedagógicos foram dominados pelo ensino em grupo, com todos os professores presentes na sala de aula em todas as sessões - mais uma manifestação de trabalho coletivo. Houve também pequenos grupos de estudo, sobre temas tais como teoria marxista. A mais importante de todas as atividades era o trabalho de campo, para a recolha de dados (CEA, 1982). No início de 1980 , e mesmo após a morte de Ruth, esse trabalho continuava possível, mas rapid-
1983 e a manifestação mais recente dessa tendência foi o seminário "Quarenta Anos de Actividade Científica do CEA", que tomou lugar em Maputo nos dias 8 e 9 de março de 2016. As atas desse evento se encontram atualmente em preparação para publicação num livro organizado pela

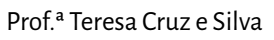
e a Dr. a Amélia Souto.

9 Outro trabalho do mesmo autor, em inglês, trata das práticas do Centro nas ciências sociais, mas é bem mais genérico e menos pessoal em sua natureza (José, 1988). 
amente virou muito perigoso por causa dos que chamávamos equivocadamente à época de "bandidos armados", ou seja, os rebeldes da Renamo. Um outro princípio pedagógico importante foi de permitir que os estudantes fizessem os seus próprios erros, quer dizer identificar uma linha de análise e sem orientação explícita dos professores, descobrir se dava certo ou não.

A primeira edição do curso, sem diploma, correu por dois anos em 1979-1980, mas em 1981 o tempo foi reduzido para um ano. Na terceira edição, em 1982, ano do assassinato da Ruth, o curso foi dividido em módulos especiais destinados aos trabalhadores em setores específicos, tais como o bancário, embora os grandes temas, como "Métodos Empíricos" e "Economia Política da África do Sul" continuassem

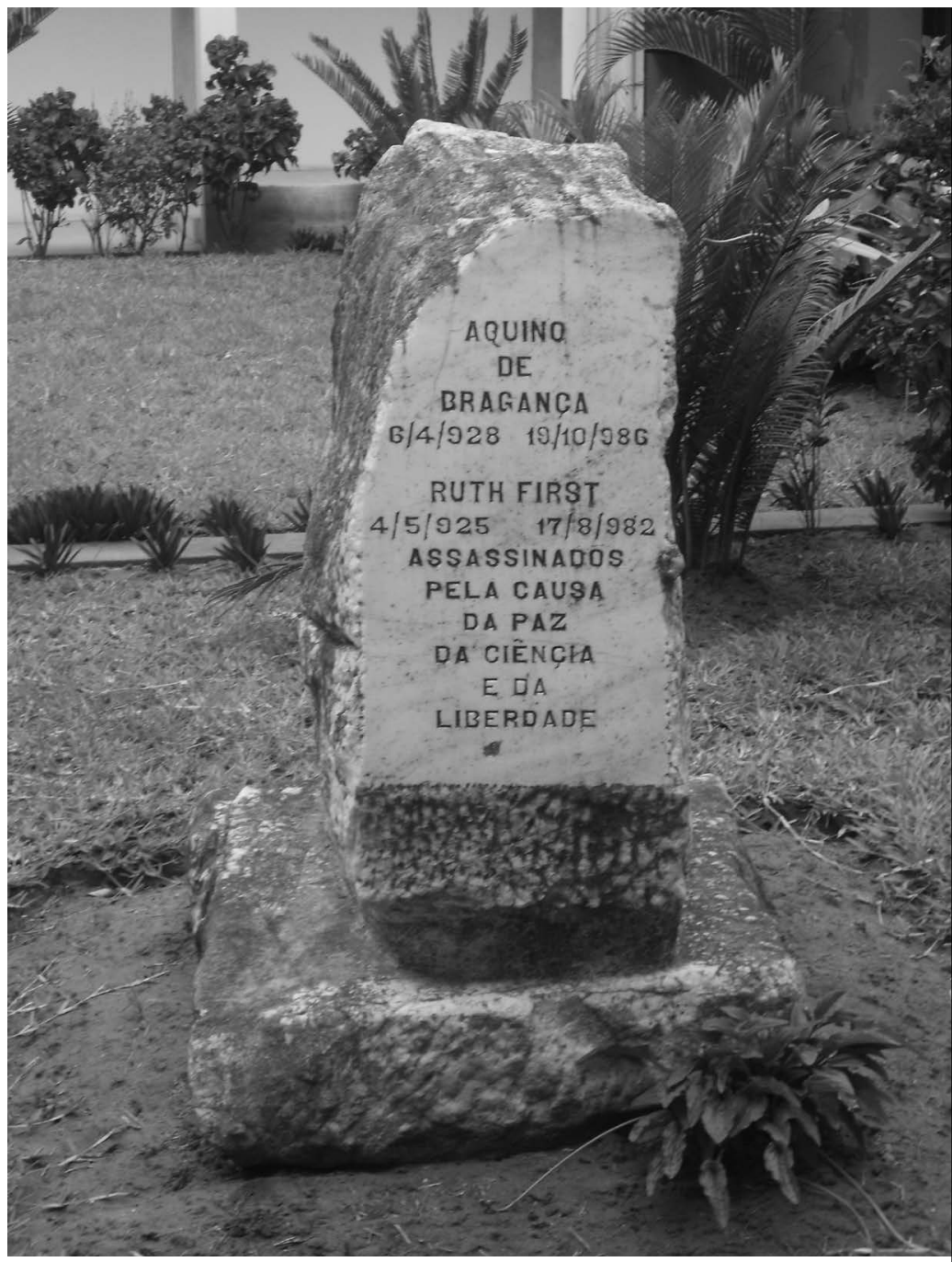
como antes. Ficou difícil nessa época identificar participantes adequadamente posicionados tanto em termos da sua experiência como o seu nível de educação formal.

O Centro realizou muitas pesquisas de escala pequena sobre temas tais como o desemprego. Mas é de salientar que a presença dos alunos nos permitiu realizar projetos muito maiores e mais ambiciosos. Um deles foi a investigação sobre algodão, realizado em colaboração com um instituto norueguês. O estudo integrou aspetos agrícolas com aspetos industriais. Duas ondas de investigação rural foram conduzidas em Nampula e Zambézia, dois estudos de fábricas nas empresas Texmoque e Texlom, além de análises sistemáticas de fontes documentais e estatísticas. Uma série de relatórios foi publicada em 1979, 1980 e 1981, com a última contribuição da Noruega aparecendo em 1982. Um desses relatórios provocou uma reação negativa nas fileiras superiores do partido, porque descreveu o uso de trabalho infantil nas plantações de algodão. Alguns exemplares com uma fotografia das crianças esperando pagamento foram retirados de circulação. Ruth, evidentemente, nunca hesitou em escrever o que ela viu, e sua prática crítica em Moçambique em apoio à revolução não era diferente

\section{Figura 2}

Lápide em memória a Aquino de Bragança e Ruth First no jardim do Centro de Estudos Africanos, Universidade Eduardo Mondlane, Maputo. Foto: Colin Darch. 
de sua prática na África do Sul como inimiga implacável do apartheid. Na sua pessoa eram articulados e integrados o rigor acadêmico, com a urgência e senso de imediatismo do jornalista.

\section{A ESCOLHA DOS TEMAS E A PRÁTICA DE PESQUISA NO CEA}

No período entre 1976 e o desastre de Mbuzini em 1986, sob a liderança do diretor Aquino de Bragança, e mais diretamente de Ruth, o CEA desenvolveu rapidamente um conjunto de práticas metodológicas e uma perspectiva críticatrabalho coletivo, integração entre investigação e ensino, ênfase em problemas práticos de produção, e um reconhecimento do caráter estreitamente conectado das economias da África Austral como um único sistema. Sem realmente ter como justificar isso cientificamente, acho possível afirmar que existiu nas décadas de 1970 e 1980 algo que se pode chamar de uma "escola moçambicana" nas ciências sociais africanas, manifestando-se tanto nos métodos de pesquisa como no engajamento político, e até a escolha de um público-leitor essencialmente moçambicano pela publicação dos relatórios de pesquisa somente na língua portuguesa e em edições policopiadas. ${ }^{10}$ Foi caracterizada, no mínimo, por uma visão global da África Austral como região; pelo engajamento crítico com o processo revolucionário em Moçambique; e pelo forte compromisso com os métodos coletivos de trabalho. Além disso, as práticas de pesquisa em coletivo no Centro ficaram, evidentemente, bastante empíricas, e nesse sentido ainda não mostraram as características essenciais do que mais tarde começaram a chamar de "epistemologia do sul" (Connell, 2007).

A escolha dos temas de pesquisa não era aleatória e não era de jeito nenhum determinada pelos interesses individuais dos seus investigadores (nem pelas orientações do Partido). Pelo contrário, os temas eram escolhidos em função de uma prática criticamente engajada das ciências sociais. Isto era explicitamente orientado, com o objetivo de criar oportunidades de intervenção nos processos políticos que visavam o fortalecimento da economia moçambicana. Cito aqui um texto nosso de 1982:

A escolha de problemas para ser investigados pelo CEA tem enfatizado questões da transformação da produção. Estes estudos de produção são importantes não só para o significado das questões de transformação que eles apresentam, mas também para a maneira na qual ajudam na construção de uma compreensão histórica dos padrões de exploração colonial, a partir do qual começa a transformação. O objetivo do Centro é, portanto, o de fornecer informações sobre as condições atuais de produção, a fim de permitir que as medidas concretas sejam concebidas, para a implementação de uma estratégia geral.
10 Acredito que a primeira pessoa a sugerir a ideia de uma "escola moçambicana", mesmo de curta duração, foi Peter Vale, professor titular sul-africano especializando-se em relações internacionais. 
Os problemas de investigação são escolhidos (...) não somente porque têm a ver com problemas específicos de transformação socialista, mas também porque as questões que os mesmos levantam podem ser utilizadas por estruturas dentro do governo e do partido. Assim, essas estruturas podem não só responderà informação, mas também ser aproveitados no seu trabalho (...) (CEA, 1982: 31).

É importante reconhecer que o foco de pesquisa do Centro não era estático ao longo do tempo. Mudou, adaptando-se às circunstâncias locais. Não foi por acaso que o primeiro grande projeto coletivo no Centro, em 1976, foi um estudo da economia política do Zimbábue, uma vez que a luta de libertação naquele país, no vulnerável flanco ocidental de Moçambique, era, sem dúvida, a principal preocupação estratégica do período. Esse projeto, concluído coletivamente no CEA antes da chegada de Ruth em 1978, foi levado a cabo sob a liderança do Aquino. Aconteceu no momento da malsucedida Conferência de Genebra sobre o Zimbábue, nos finais de 1976, para tentar resolver o problema da revolta dos colonos brancos naquele país." A reunião em Cenebra foi mediada pelos britânicos e trouxe à mesa o governo branco de Primeiro-Ministro rodesiano, lan Smith, e os vários movimentos africanos de libertação, a procura de um acordo de cessar-fogo e um caminho para uma nova constituição democrática e não-racial.

O Centro foi convidado a escrever um "documento de referência" sobre a economia política do país, que poderia apoiar as posições da chamada "frente patriótica", na altura uma aliança ad hoc entre ZANU e ZAPU - sobretudo, o CEA foi chamado a compor o documento em muito pouco tempo. ${ }^{12}$ Aquino reuniu um grupo de jovens pesquisadores, que à altura estavam a dar aulas em diferentes departamentos acadêmicos, para que eles fizessem durante poucas semanas um trabalho muitíssimo intensivo de pesquisa e escrita - eles não eram, nesse período, quadros do Centro em tempo integral. Esse projeto estabeleceu um precedente para o estilo de trabalho coletivo e para o engajamento crítico em questões políticas urgentes. $O$ estudo mimeografado foi mais tarde publicado em livro impresso, com edições em Lisboa tal como em Maputo (CEA, 1978).

Numa entrevista recente, Rob Davies, ex-pesquisador do CEA e agora Ministro do Comércio e Indústria da África do Sul, enfatizou esse aspecto de adaptabilidade por parte do Centro não só nos "tempos heroicos", mas até a década 90:
11 Em 1965, o governo branco minoritário, preocupado com a crescente demanda por direitos políticos da população africana, promulgou uma Declaração Unilateral de Independência (UDI). Logo depois, os movimentos de libertação pegaram em armas e desencadearam uma luta pela democratização.

12 ZANU era um movimento de libertação, a União Africana Nacional do Zimbábue, estabelecida em 1963 e liderada por Robert Mugabe (1924-), e ZAPU era a União Africana Popular do Zimbábue, estabelecida em 1961 e liderada por Joshua Nkomo (1917-1999). Em 1987, os dois movimentos se fundiram para formar ZANU-

$\mathrm{PF}$, o partido em poder até hoje.

Havia uma abordagem de estudos estratégicos em torno da guerra de desestabilização, e acho que estávamos entre os primeiros a iniciar esse tipo de pesquisa (...). Mais tarde (...) a guerra ganhava ritmo, e começou a ter um impacto em diversos países [, mas o] nosso trabalho centrouse especialmente na dinâmica Moçambique-África do Sul e procuramos compreender profundamente a estratégia da África do Sul, as possibilidades 
de que essa estratégia ia continuar e até assumir novas formas, a natureza verdadeira do nosso adversário - todas essas questões entraram em nossa pesquisa ... começou assim. Pode-se dizer que foi uma espécie de "escola moçambicana"- mas eu preferiria dizer que era uma espécie de estudos estratégicos que mais tarde virou uma tentativa de desenvolver uma economia política da região. Mas foi assim que começamos (Darch, 2017, no prelo).

O trabalho no Centro sob a direção de Aquino e Ruth, e depois, pode ser dividido em vários períodos, de duração desigual, mas que são importantes para a compreensão do desenvolvimento dos métodos pedagógicos e de investigação. O período de "pré-história" abrange a fase em que Aquino, sozinho na direção, organizou cerca de doze jovens pesquisadores moçambicanos, majoritariamente historiadores de formação, para começar investigações sobre a história do subsistema regional da África Austral, enfatizando aspetos tais como a economia moçambicana. Nos finais desse curto período, trabalhando coletivamente, um subgrupo especializado em economia política produziu o relatório sobre Zimbábue.

Um segundo período é definido pela chegada de Ruth First, pela primeira vez, numa estadia de curta duração em 1977, em li cença da Universidade de Durham na Inglaterra. Sua função nesse momento era a direção de um projeto, também coletivo, de pesquisa sobre o impacto do sistema de trabalho migratório na economia política rural do sul de Moçambique, especificamente, a província de Inhambane. Foi esse o projeto que tem resultado, através dos anos, nas várias edições do O mineiro moçambicano, a mais recente publicada no Recife (First, 2015).

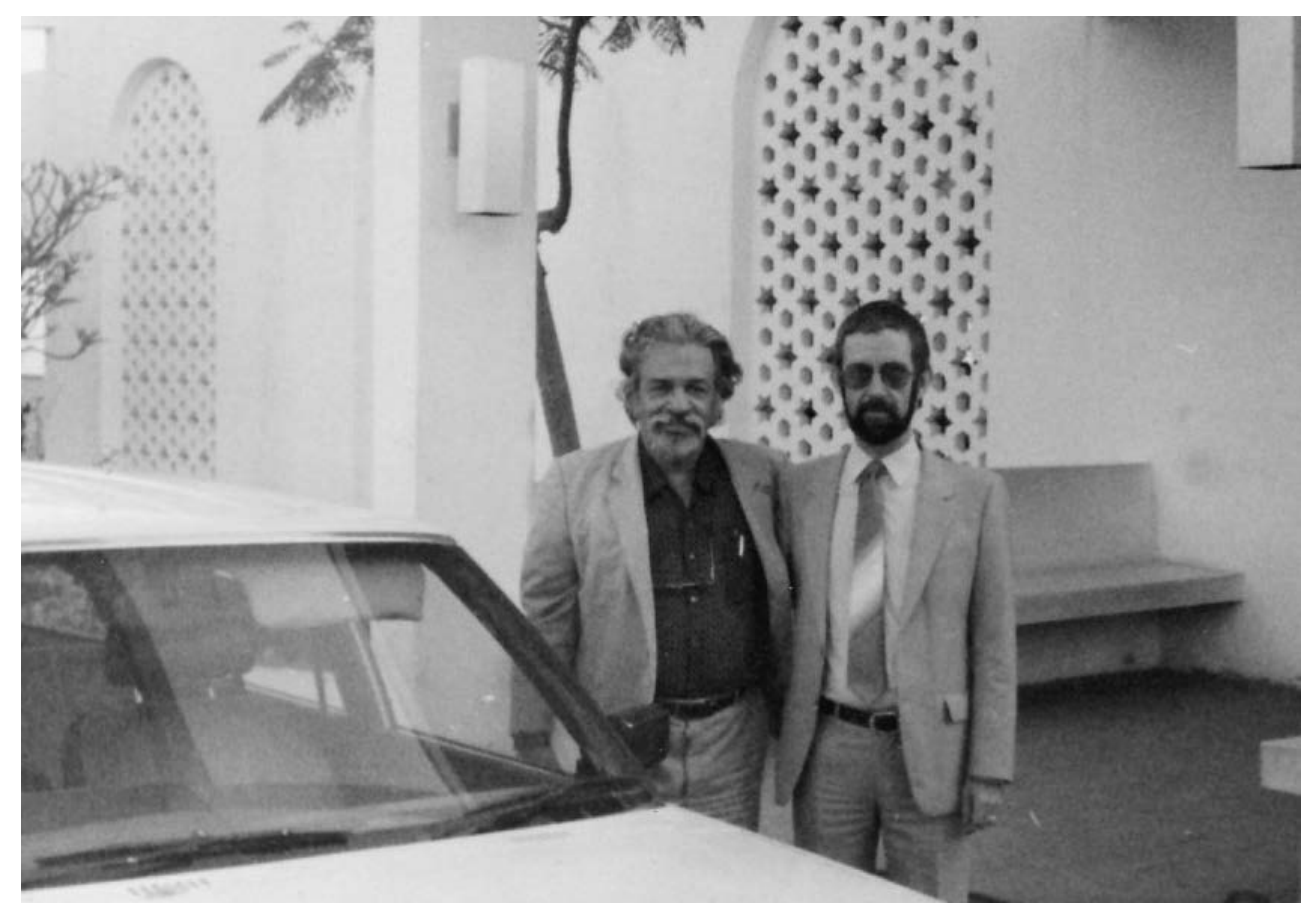

\section{Figura 3}

Aquino de Bragança (a esquerda) com o autor (a direita) em Dar es Salaam, em outubro ou novembro de 1985 numa viagem para entrevistar o então Presidente de Tanzânia, Julius Kambarage Nyerere (1922-1999). Foto: Yussuf Adam, coleção particular do autor. 
É de salientar que Ruth First não tinha responsabilidades administrativas no Centro quando dirigiu essa investigação. Por isso, nas palavras de meu antigo colega, o economista belga Marc Wuyts, "ela tinha a oportunidade de executar o projeto do início até ao fim (...) O mineiro absorveu todas as suas energias e toda a sua atenção" (Wuyts, 2012).

Esta experiência evidentemente exerceu uma forte influência sobre as metodologias e epistemologias de pesquisa adotadas no Centro após os finais de 1978. Naquele momento, os pesquisadores do CEA, cerca de doze profissionais ao todo, ainda ocupavam cargos acadêmicos em determinadas faculdades e departamentos da universidade - não foram empregados permanentes ou de tempo integral no Centro. Assim, O mineiro, tal como as pesquisas anteriores sobre o Zimbábue, diferiam dos projetos posteriores na forma da sua organização e no seu destacamento ou separação de qualquer programa de ensino dentro do Centro.

Um novo período começou quando Ruth assumiu uma posição permanente como diretora científica do CEA, em 1978. Aquino permaneceu no seu cargo de diretor. Aquino e Ruth se conheciam há anos, como militantes e jornalistas nas mesmas fileiras, no período em que Aquino estava trabalhando em Argel na Conferência das Organizações Nacionalistas das Colônias Portuguesas (CONCP), um órgão de coordenação entre a Frelimo, o MPLA, o PAICC e o MLSTP - os principais movimentos de libertação que lutavam contra o colonialismo português. ${ }^{13}$

Ao mesmo tempo em que era diretor do Centro, Aquino, conhecido nas fileiras da Frelimo como o "submarino", envolveu-se frequentemente em atividades diplomáticas meio clandestinas sobre questões delicadas. Nesse período, também, havia pouco apoio administrativo eficaz, de modo que Ruth tinha que perder o seu tempo verificando se havia chapas suficientes para imprimir os nossos textos mimeografados, ou que a fotocopiadora funcionava, se tínhamos escritórios para toda a gente, e assim por diante. Como resultado, ela foi menos envolvida no planejamento direto ou na execução cotidiana das atividades de investigação a partir dos princípios de 1979. Em contrapartida, conseguiu montar uma equipe, um quadro permanente de pesquisadores jovens, moçambicanos e estrangeiros, que foram vistos como "militantes de várias nacionalidades" na frase internacionalista e inesquecível de Aquino. Numa análise retrospectiva, é possível ver que a falta de quadros nacionais, e ainda mais importante, a falta de esforço de recrutá-los - a grande maioria dos estudantes no Curso de Desenvolvimento regressaram ao Estado e Partido-era um ângulo morto nosso. Não fui o único quadro recrutado a partir de Dar es Salaam, onde Ruth tinha sido professora visitante no início da década de 70. Entre os outros camaradas que tinham trabalhado lá, lembro-me do economista belga Marc Wuyts, do historiador congolês Jacques Depelchin,
13 Frelimo é a Frente de Libertação de Moçambique; MPLA, o Movimento Popular de Libertação de Angola; PAICC, o Partido Africano da Independência da Guiné e Cabo Verde; e MLSTP, o Movimento de Libertação de São Tomé e Príncipe. 
do sociólogo e historiador Gary Littlejohn, do sul-africano Dan O'Meara, e da cientista política italiana, Anna Maria Gentili. Após a morte de Ruth em 1982, Aquino consolidou a organização do Centro em núcleos de pesquisa - a Oficina de História, o Núcleo da África Austral, etc. - e constituiu um Conselho de Direção que se reunia semanalmente.

Esse mesmo problema da "falta de esforço" de recrutar quadros nacionais abre a questão da africanização do Centro e da sua equipe. O compromisso bem conhecido de Frelimo para com o "não-racismo" se refletiu nas práticas e no discurso do CEA, mas, mesmo assim, a composição e a hierarquia do Centro - certamente no período em discussão - não constituam reflexo adequado das realidades da demografia moçambicana. Isso pode ter sido inevitável numa situação pós-independente na qual faltavam trabalhadores negros qualificados para as mais diversas funções. De qualquer jeito, não era um tópico discutido abertamente naquele momento-supostamente porque o discurso dominante enfatizou questões de classe e nem tanto da raça. Isso mudou um pouco quando Sérgio Vieira tornou-se diretor, como depois afirmou Rob Davies:

Quando Sérgio Vieira entrou, uma das suas preocupações, do que ele se queixava - e tinha razão - era que a instituição não era suficientemente "moçambicana"; havia muitos cooperantes estrangeiros que estavam "fazendo as suas coisas" sem qualquer treinamento, acompanhamento ou orientação de moçambicanos. Acho que essa foi uma fraqueza (...) (Darch, 2017, no prelo).

Por fim, ainda nesta retomada dos trabalhos do CEA, cumpre registrar algumas das atividades mencionadas no relatório de 1985, acima referido, que oferece uma lista detalhada das atividades de CEA entre 1979 e 1985, incluindo uma ampla variedade de tópicos: cursos anuais de economia rural nas Faculdades de Veterinária, Agronomia, Biologia e no Ministério da Saúde; sobre a história da África na Faculdade de Educação, em 1982; palestras sobre a história das zonas libertadas na Faculdade dos Antigos Combatentes e Trabal hadores de Vanguarda, em 1983; a participação deste autor na Licenciatura em História com Especialização em Documentação no Arquivo Histórico de Moçambique entre 1984 e 1985; e cursos de curta duração sobre a economia da África Austral nos Ministérios de Informação, Negócios Estrangeiros e Defesa, bem como na sede do Partido Frelimo. Um curso especial sobre desenvolvimento e subdesenvolvimento foi organizado por Armando Cuebuza, então membro do Bureau Político. Os tópicos de pesquisa incluíam: o desemprego, as redes de transporte, a comercialização agrícola, a produção de algodão, a "contentorização" no porto (ou seja, sua adaptação para o sistema de containers), a produção de chá em Curuè e problemas nas aldeias comunais em Cabo Delgado (UEM, 1985: 9-11). 


\title{
AS CRÍTICAS
}

Na realidade, a escolha dos temas de investigação pelo Centro não se dava em função das preocupações do Partido Frelimo, mas, pelo contrário, em função do que era avaliado pelo coletivo como problemas concretos de produção. Algumas vezes, o Centro se defendeu contra pressões exteriores, argumentando que um determinado projeto era de "interesse do Partido", mas evidentemente isso não implicava que o Partido tinha domínio sobre a investigação. Essa dinâmica, mal-entendida, provocou algumas críticas de caráter mais ou menos hostil, não apenas na África do Sul-à altura ainda sob o controle de um regime minoritário branco-, mas também em outras partes do mundo acadêmico, especialmente no Reino Unido e nos EUA. Essas críticas, em geral, não se engajaram de uma forma concreta com os textos de pesquisa produzidos (em números relativamente substanciais) pelo Centro, mas atacaram - em termos mais ou menos contundentes-os motivos políticos dos próprios pesquisadores estrangeiros. Tal como as pesquisas de outros em situações semelhantes, o nosso trabalho foi interpretado como sendo simplesmente determinado pelas prioridades pontuais do Estado ou do Partido. O britânico Tom Young escreveu desdenhosamente em 1988 que

\author{
Por muito tempo após a independência uma boa parte da literatura \\ acadêmica (...) sobre Moçambique foi produzida pelos "pés vermelhos" \\ [ou seja, pessoas politicamente comprometidas com os objetivos \\ do governo]. Esta literatura (...) embora bastante útil, tem de \\ ser avaliada cautelosa e criticamente (Young, 1988: 165).
}

Young parece ter apropriado o termo "pés vermelhos" de um texto reflexivo sobre a relação entre a guerra popular e a revolução social, escrito por Chabal, no qual o autor descreve sua ansiedade de ser assim classificado enquanto pesquisava na Guiné em 1979 (1983: 104-105). O artigo de Chabal não é, de modo algum, hostil a uma prática de pesquisa criticamente comprometida per se e, de fato, conclui argumentando que "não existe uma razão sólida para pensar que as revoluções não podem acontecer" nos países africanos, mas que há grandes probabilidades contra isso (1983: 122).

O antropólogo francês Ceffray caiu numa armadilha semelhante, argumentando erroneamente que as conclusões das pesquisas do CEA eram suspeitas por causa da orientação política dos pesquisadores. Este argumento baseia-se, em primeiro lugar, num pressuposto implícito de que a totalidade das atividades do Centro consistia no Curso de Desenvolvimento e os trabalhos do campo associados. Em segundo lugar, Geffray avança uma implícita concepção positivista de uma subjetividade tendenciosa na nossa pesquisa, como se os resultados da 
pesquisa dependessem dos preconceitos do pesquisador e não de uma interação entre teoria, evidência e a reavaliação constante das questões iniciais de pesquisa. Ceffray também seguiu argumentando que o Centro se submeteu aos objetivos estratégicos da Frelimo, chegando a tratar isso como um processo linear de implementação de ordens, vindo de diferentes seções das estruturas estatais (1988: 74-75). Entretanto, as pesquisas do CEA mostraram, em diversas ocasiões, atitudes reprovadoras em relação a determinados aspectos da política. Às vezes, o Centro necessitava da proteção do Magnífico Reitor, Fernando Canhão, e de Aquino por causa de posições indesejadas pelo Partido. Um exemplo concreto disso foi quando o Centro publicou um relatório com uma fotografia de trabalho infantil na fazenda estatal de Metochéria na província de Nampula.

Seria impossível discutir análises críticas do trabalho do CEA no período em foco, sem citar o trabalho do pesquisador moçambicano Carlos Fernandes, que dedicou o seu trabalho de diploma ao nível de licenciatura ao Centro (Fernandes, 2003). Depois, realizou um doutoramento sobre o mesmo assunto na UFBA (Fernandes, 2011) e, em seguida, publicou uma série de artigos em português, francês e inglês sobre o tema (Fernandes, 2010, 2012, 2013). Como os outros analistas, Fernandes parece preocupado principalmente com a questão teórica da relação entre o poder estatal e a produção do conhecimento, mais do que uma leitura cuidadosa da pesquisa em si. De fato, em sua tese de doutorado ${ }^{14}$, ele afirma que seu argumento central é esse:

(...) as "condições sociais", e os processos (muitas das vezes conflitivos) da produção de conhecimento adquiriram dinâmicas próprias que problematizaram os pressupostos dentro dos quais o CEA devia produzir conhecimento e que isso explicaria não só as especificidades do trabalho científico do CEA (por exemplo a relação de proximidade/distanciamento do CEA com o poder) como também as condições em que as ciências sociais ganharam contornos em Moçambique com o modo privilegiado de produção de conhecimento sobre a sociedade (por exemplo, a emergência no pósindependência de uma nova forma de se fazer pesquisa) (2011:16-17).

Num texto posterior sobre a Oficina de História, ele adota uma linha análoga, salientando que o principal objetivo do trabalho histórico do Centro era

(...) a construção de uma narrativa histórica do passado colonial tardia e da luta armada da Frelimo [que funcionaria] como uma resistência teórica à historiografia colonial e como uma recuperação do sujeito histórico africano, mas também como um ponto essencial na legitimação política e a perpetuação do regime da FRELIMO no Moçambique pós-independente (2013: 145, grifo meu).

14 Pela bibliografia referida, parece que Fernandes, infelizmente, teve acesso apenas a um punhado dos relatórios de pesquisa do Centro. 
O texto segue, afirmando que essa realidade "ofereceu clareza e um forte sentido de propósito aos historiadores do CEA" (2013: 145), o que talvez pode ser entendido como uma versão mais suave do comentário de Geffray de que o trabalho do Centro "confortait le discours du pouvoir" (Geffray, 1988: 85). No entanto, embora Fernandes critique o papel político do Centro, também reconhece que os pesquisadores ocuparam o que ele chama de "uma posição ambivalente", adotando posições críticas (Fernandes, 2013: 157).

O Centro tem também sido representado como implacavelmente hostil às abordagens antropológicas da pesquisa nas ciências sociais. Ainda em 2000, Peter Fry menciona o que ele denomina "o poder enorme" do CEA no âmbito de um "marxismo anti-antropológico" que existia em Moçambique neste período. ${ }^{15}$ Contudo, contextualmente, a pesquisa nas ciências sociais era extremamente fraca: portanto, o "poder enorme" do Centro foi exercido numa arena bastante pequena. Além disso, parece provável que, para o Reitor Ganhão e para Aquino, o CEA fosse uma solução ad hoc e de curto prazo para o problema da impossibilidade de estabelecer uma Faculdade de Ciências Sociais. Da mesma forma, embora existisse uma forte simpatia pela "crítica da antropologia" (por exemplo, Depelchin, 1982), um elemento na oposição do CEA ao estabelecimento de um departamento de arqueologia e antropologia no início da década de 1980 teve que ver também com os riscos de estabelecer um polo alternativo de atração para financiamento, recursos, e pessoal. ${ }^{16}$

As críticas de Young e Geffray revelam inadvertidamente o seu desconforto com a rejeição ao positivismo do Norte, implícita nas práticas de pesquisa do Centro. É talvez anacrônica pensar que essas mesmas práticas rejeitaram do mesmo modo a "divisão global do trabalho" em que o "papel da periferia [era] fornecer dados" para os centros do Norte, depois explorar na produção de uma teorização essencialmente nomotética (Connell, 2013: 211). Como Connell também argumenta, uma justificação da "epistemologia do sul" tem mais a ver com práticas de conhecimento que com teoremas diferentes (2013: 219).

Alguns elementos da trajetória da pesquisa que levaram a cabo $O$ mineiro moçambicano podem ser citados para ilustrar este ponto. O texto era, sem dúvida, o mais importante produzido pelo Centro na década 80, um estudo da sociedade fornecedora, num sistema de trabalho migratório, na província de Inhambane na zona Sul do Save. É importante lembrar que, na década de 1970, uma percentagem extremamente elevada da força de trabalho nas minas sul-africanas foi composta por homens de Moçambique, Malaui e Lesoto. O estudo tinha uma perspectiva histórica, descrevendo os fluxos de trabalho a partir de 1902, no início do século XX, bem como analisando o funcionamento do sistema na economia camponesa moçambicana. A questão de pesquisa principal centrou-se não nas minas sul-africanas, mas na economia política do sistema de
15 No mesmo texto, Fry cita Geffray, com aprovação, no sentido de que Aquino e Ruth teriam entrado no "sérail des héros du Bureau politique" (Fry, 2000: 129 fn).

16 Numa reunião à altura, Aquino aceitou a necessidade de separação da disciplina de arqueologia, mas não se exprimiu sobre a questão da antropologia. 
exportação de mão-de-obra no sul de Moçambique.

A pesquisa constatou que quase a totalidade dos homens nas províncias do Sul do Save foi para as minas sul-africanas - exceto pelas pessoas com deficiência física e os idosos. Os rendimentos agrícolas eram tão baixos que uma interdependência mútua se desenvolvera entre a produção camponesa, por um lado, e a migração de trabalhadores às minas, por outro-um sistema fortemente apoiado pela política portuguesa. Daí a dependência da agricultura familiar sobre as remessas dos mineiros ser tão forte que só uma transformação dramática da produção agrícola permitir uma ruptura radical.

Uma versão inglesa foi posteriormente publicada sob o título Black Gold por uma editora comercial britânica, atribuindo a autoria exclusivamente a Ruth First. A atribuição era exigência da empresa editora, impulsionada ostensivamente por uma lógica de marketing na qual o nome de Ruth venderia mais exemplares. O caso ilustra, de forma clara, a imposição de uma prática dominante de comunicação científica, uma prática de autoria individualista, uma "prática" que era fundamentalmente al heia ao modo de produção de conhecimento coletivo do Centro. Assim, o texto do Mineiro foi lançado no "mundo" na língua dominante daquele mundo, mas foi reconfigurado em termos de uma distinção entre pesquisa engajada e teoria acadêmica, o que exigiu sua integração numa tradição diferente de autoria, que deixou pouco espaço para a ideia de um coletivo meio-anônimo. ${ }^{17}$

Antes de concluir, é importante mencionar as investigações históricas do CEA na chamada Oficina de História. Essa foi provavelmente a primeira vez que a palavra portuguesa "oficina" foi utilizada para denominar uma espécie de seminário acadêmico naquele contexto. A Oficina de História - que tinha participantes de fora do Centro e até mesmo fora da universidade - trabalhou inicialmente sobre a trajetória da luta armada, mas rapidamente se expandiu para outras áreas de história cultural. Tudo começou com uma série de seminários semanais; a maioria das apresentações já está, infelizmente perdida. Incluíram, por exemplo, uma colaboração de Paulo Soares com Malangatana sobre arte e política na luta, uma antologia de artigos de O Africano de Soares e Zamparoni, e outras (Soares e Zamparoni, 1992). A Oficina publicou também a revista Não Vamos Esquecer e relatórios baseados na pesquisa de campo realizada nas antigas zonas libertadas de Cabo Delgado.

Pouco antes de sua morte em Mbuzini, Aquino completou um artigo escrito em colaboração com Jacques Depelchin, que foi publicado em português e inglês (Bragança e Depelchin, 1986). Argumentaram contra a idealização da Frelimo e em favor de uma abordagem diferente da recente história moçambicana. Ao fazê-lo, discutiram abertamente as divisões dentro das fileiras da Frelimo que surgiram após a independência. Argumentaram que o
17 Meus agradecimentos a um dos pareceristas anônimos por esta sugestão. 
período pós-independência não devia ser tratado isoladamente do que aconteceu antes, e criticaram argumentos que trataram a luta pela independência como um sucesso sem qualificação, simplesmente porque resultou na vitória. Defenderam uma análise das contradições que levaram a Frelimo à situação de então, usando documentos oficiais para mostrar as críticas sendo feitas dentro do Partido. Os autores perguntaram por que razão a Frelimo virou menos revolucionária no momento em que herdou o aparelho do Estado colonial.

Esta foi efetivamente a primeira tentativa analítica, publicamente divulgada, de reconhecer e lidar com divisões internas dentro da Frelimo, num contexto no qual o discurso público do Partido construiu uma fachada de frente unida. Neste respeito, apesar de Geffray e Young, foi precisamente o CEA que estava fazendo uma tentativa genuína de levar à cena pública uma discussão séria e aberta sobre o que o impasse de 1986 realmente representou.

O melhor da pesquisa do CEA, parece-me, foi a investigação crítica, engajada e emancipatória. Nunca, ou quase nunca, tratou-se de um mero exercício de positivismo. $O$ objetivo era, precisamente, ajudar a mudar as coisas. $O$ trabalho de Ruth e seus métodos de análise não foram esquecidos. Publicações continuaram a aparecer na década de 1990 e 2000, devendo muito ao seu estilo. Mas mais importante ainda, a visão da África Austral como sistema, com sua própria dinâmica regional, é manifesta claramente nesse conjunto de trabalhos. Eu acho que essa continua a ser a melhor maneira de entender a atualidade do meu país, a África do Sul, e dos seus países vizinhos.

\section{CONCLUSÃo}

Comecei este ensaio colocando a questão de como teorizar a minha própria trajetória intelectual - na verdade, a minha própria vida - a partir da posição socrática de que "só sei que nada sei". Nesse caso, o quadro para uma tal teorização deve ser o encontro entre a presunção irreflexiva de dominação - característica dos ingleses, dos homens, dos brancos, dos acadêmicos e afinal de mim-com diferentes línguas, raças, gêneros, e sistemas de pensamento. É importante reconhecer que esses encontros não estão livres de relações de poder, e que o mero voluntarismo ou boa vontade não pode mudar isso. Também pode ser que um tal exercício, livre de vaidade ou da promoção de uma autoimagem, seja impossível, ou não valha a pena. Entretanto, Sócrates também nos ensina que

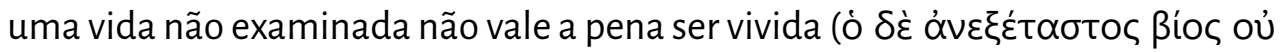

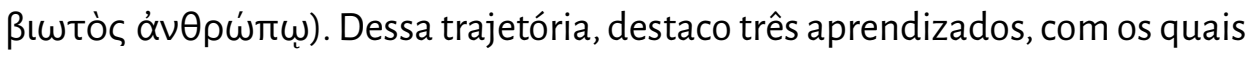
gostaria de encerrar o artigo.

Em primeiro lugar, portanto, uma prática que, creio eu, foi concebida pre- 
cisamente para o ocidental vivendo em terras estranhas: esvaziar a mente dos seus pensamentos tanto quanto possível e pelo maior tempo possível, viajar sem expectativas. De fato, os falantes de suaíli têm um ditado que diz que uma pessoa não pode aprender nada quando a sua boca está cheia de suas próprias palavras. Esta, parece-me, é uma prática característica do melhor da antropologia como disciplina, e exige rigor e paciência, bem como uma disposição para acolher o desconforto.

Em segundo lugar, o imperativo de abrir os sistemas de informação a todo o mundo, de preservar o conhecimento, de aprender línguas e as formas de pensar que as acompanham. $\mathrm{O}$ impulso capitalista é sempre privatizar o conhecimento, reificar e comercializar a cultura, construir silos de informação para melhor controlar sua natureza subversiva. Mas o que foi chamado de "tecnologia disruptora" nos oferece um vislumbre de esperança - a Web, mas não a Internet, sistemas de compartilhamento em vez da expansão da chamada "propriedade intelectual" -, que de fato nunca pode ser totalmente detida por ninguém.

Terceiro, o reconhecimento de que quase todas as vidas são transversais, todo o olhar é cruzado. Homem aventureiro da etnia nhanja cujo pai nasceu em Moçambique, meu sogro viajou para Rodésia do Norte nos tempos coloniais e lá se encontrou com uma bela mulher muçulmana ajaua, já casada, com quem ele fugiu para o Congo. Destemidos por diferenças de idioma, de idade, cultura ou religião, o casal depois mudou-se para Tanganhica e criaram nove filhos. Meu sogro falava pelo menos quatro línguas, e morreu em 2014 alguns dias depois de seu $100^{\circ}$ aniversário. Para o casal, não importava o presente etnográfico, não importava a falta de agência na vida africana, não importava a identidade tribal, nem as fronteiras coloniais. Como Marx escreveu em 1852, as pessoas "fazem a sua própria história, mas não a fazem (...) em circunstâncias escolhidas por eles próprios" (Marx, 1982: I, 417).

Colin Darch, atualmente aposentado, é investigador emeritus na University of Cape Town e Honorary Research Fellow do Human Sciences Research Council da África do Sul. Em 2016, foi professor visitante na UFPE e, em 2017, professor visitante na Universidade Pedagógica em Maputo, Moçambique. Doutorado em história, é webmaster do site Mozambique History Net, e autor de diversos trabalhos sobre Moçambique contemporâneo. $O$ seu livro $O$ continente demasiado grande foi publicado pela UFPE no Recife em 2016. 


\section{REFERÊNCIAS BIBLIOGRÁFICAS}

BRAGANÇA, Aquino

2014 "Independência sem descolonização: a transferência do poder em Moçambique, 1974-1975". In MONDAINI, Marco (org.). Sonharé preciso: Aquino de Bragança, independência e revolução na África portuguesa, 19801986. Recife, UFPE, pp. 91-111.

BRAGANÇA, Aquino e O'LAUGHLIN, Bridget

1996 "O trabalho de Ruth First no Centro de Estudos Africanos". Estudos Moçambicanos, n. 14: 113-126.

BRACANÇA, Aquino e DEPELCHIN, Jacques

1986 "Da idealização da Frelimo à compreensão da história de Moçambique". Estudos Moçambicanos, n.5/6: 29-52.

\section{CENTRO DE ESTUDOS AFRICANOS (CEA)}

1978 A questão rodesiana. Lisboa, Iniciativas Editoriais.

1982 "Strategies of Social Research in Mozambique". Review of African Political Economy, vol. 9, n. 25.

CHABAL, Patrick

1983 "People's War, State Formation and Revolution in Africa: a Comparative Analysis of Mozambique, Guinea Bissau, and Angola". Journal of Commonwealth and Comparative Politics, vol. 21, n. 3:104-125.

CONNELL, Raewyn

2007 Southern Theory: Social Science and the Global Dynamics of Knowledge. Cambridge, Polity.

2013 "Using Southern Theory: Decolonizing Social Thought in Theory, Research and Application". Planning Theory, vol. 13, n. 2: 210-223.

DARCH, Colin

2014 "Remembering Ruth First at the CEA". Review of African Political Economy, vol. 41, n.139: 38-43.

2016 O continente demasiado grande: reflexões sobre temáticas africanas contemporâneas. Recife, Editora UFPE.

2017, no prelo Entrevista inédita com Rob Davies, a ser editada em Maputo nas atas do seminário "Quarenta Anos de Atividade Científica do CEA". 


\section{DEPELCHIN, Jacques}

1982 "Antropologia e história africana à luz da história da Frelimo". Trabalhos de Arqueologia e Antropologia, Maputo, n.2: 1-32.

FERNANDES, Carlos

2003 Saber, podere ideologia na produção científica do CEA, 1975-1984. Maputo, trabalho de conclusão de licenciatura em sociologia, Universidade Eduardo Mondlane.

2010 "Actualité, urgence et travail collectif dans l'émergence d'un nouveau champ du savoir au Mozambique: Le Cas du Centre des Etudes Africaines, 1976-1986". Identity, Culture and Politics, vol. 11, n. 2: 71-86.

2011 Dinâmicas de pesquisa em ciências sociais no Moçambique pós-independente: 0 caso do Centro de Estudos Africanos, 1975-1990. Salvador, tese de doutorado, Universidade Federal da Bahia.

2012 "Actualidade, urgência e colectivo na emergência de um novo campo de saber em Moçambique: o caso do CEA, 1976-1986". In CRUZ E SILVA, Teresa; COELHO, João Paulo Borges; e SOUTO, Amélia Neves de (orgs.). Como fazer ciências sociais e humanas na África: questões epistemológicas, metodólogicas, teóricas e políticas. Dakar, CODESRI, pp. 199-124.

2013 "History writing and state legitimisation in post-colonial Mozambique: the case of the History Workshop, Centre for African Studies, 1980-1986". Kronos, n. 39: 131-157.

FIRST, Ruth (org.)

2015 O mineiro moçambicano: um estudo sobre a exportação de mão de obra em Inhambane. Recife, Editora UFPE.

FRY, Peter

2000 "Cultures of Difference: The Aftermath of Portuguese and British Colonial Policies in Southern Africa". Social Anthropology, vol. 8, n. 2: 117-143.

\section{GEFFRAY, Christian}

1988 "Fragments d'un discours du pouvoir, 1975-1985: Du Bon usage d'une méconnaissance scientifique". Politique Africaine, n. 29: 71-85.

HOUNTONDJI, Paulin

2008 "Conhecimento de África, conhecimento de africanos: duas perspectivas sobre os estudos africanos". Revista Crítica de Ciências Sociais, vol. 80: 149-160. 
JOSÉ, Alexandrino

1988 "The Research Capital of the Centre of African Studies: A Contribution Towards the Understanding of the Mozambican Social Training in Its Time and Space". Conferência apresentada no seminário Contemporary Affairs and Processes in South Africa, Harare, 6 a 8 de dezembro.

MARX, Karl e ENGELS, Friedrich

1982 Obras escolhidas em três tomos. Lisboa, Edições Avante.

MAZRUI, Ali

1967 "Tanzaphilia". Transition, n.31: 20-26.

RIBEIRO THOMAZ, Omar

2012 "Lobolo e trabalho migratório: reprodução familiar e aventura no sul de Moçambique". In TRAJANO FILHO, Wilson (org.). Travessias antropológicas: estudos em contextos africanos. Brasília, ABA Publicações, pp.221-239.

ROAPE

2014 Review of African Political Economy, vol.41, n.139.

SOARES, Paulo e ZAMPARONI, Valdemir

1992 "Antologia de textos do jornal O Africano, 1908-1919". Estudos AfroAsiáticos, n. 22: 127-178.

UNIVERSIDADE EDUARDO MONDLANE (UEM)

1985 O Centro de Estudos Africanos de 1976 a 1985. Maputo, UEM/CEA.

Policopiado.

WIEDER, Alan

2013 Ruth First and Joe Slovo in the War Against Apartheid. Auckland Park, Jacana.

WUYTS, Marc

2012 Comunicação particular, 3 de junho.

YOUNG, Tom

1988 "The Politics of Development in Angola and Mozambique". African Affairs, n. $347: 165-184$ 


\section{ABSTRACT}

This article uses the career of the author as a case study deploying the anthropological concepts of transversality and the crossed gaze. The author examines his own experience of working in a research centre in Mozambique in the 1980s, during a post-independence armed conflict with a rebel group supplied and supported by apartheid South Africa. An English-speaker with some years of experience of working in other African countries, he arrived in Mozambique in 1979 unable to speak Portuguese or to distinguish the local features of daily life from those inherited from the colonial power, since both were alien to him. In addition, the research and pedagogical practices used in the Centre of African Studies were innovative and unusual. The author draws three conclusions from this experience: that it is necessary to approach a new culture and a new language as free as possible from prior expectation, as anthropologists normally attempt to do; that in Africa at least, we are now, forty years later, living in an epoch when the open flow of information and experience is increasingly under threat, and with them the possibility of transversality; and that although we live in circumstances and material conditions that are beyond our control, as Marx points out, we make our own choices about our own trajectories.

Recebido em 30 de maio de 2017. Aceito em 6 de novembro de 2017.

\section{KEYWORDS}

Mozambique, Research centres, Cross-Cultural Experiences, Centro de Estudos Africanos (Maputo), South Africa, Documentation, Aquino de Bragança, Ruth First 